\title{
Numerical modelling of heat flows in the upper blast furnace of the electric arc furnace
}

\author{
Richard Lenhard ${ }^{1, *}$, Milan Malcho ${ }^{1}$, Peter Durčanský ${ }^{1}$, Katarina Kaduchová ${ }^{1}$ \\ ${ }^{1}$ University of Zilina, Department of Power Engineering, 01026 Zilina, Slovakia
}

\begin{abstract}
Contributing shows one of the alternatives to use the waste heat from an electric furnace hat with subsequent use for the need for heating water preparation and central heating. In a contribution is presents a numerical model of heat flows from electric arc furnace designed for, into a cooled furnace from which waste heat is led to the central heating system. The model was developed implementing the finite volume method in ANSYS-Fluent program code.
\end{abstract}

Keywords: heat flow, arc furnace, numerical modelling, heat recovery

\section{Background}

Sustainable energy supply, energy price development and legislative measures in the environmental field are factors that clearly encourage such technical solutions that are geared towards low- and medium-term waste heat saving. Waste heat as source of thermal energy is advantageous to reuse as secondary energy source preferably in the technologies that produce it. Waste heat arise in general as a consequence of fuel and energy consumption in technological processes in which they are not used because their parameters are inappropriate for the maintained technology. However, waste heat can be a source of energy for other devices in which they can wholly or partly replace fuel or energy.

One way to reduce the cost of thermal energy is to recover waste heat through heat exchangers of different designs depending on the application. Technological processes characterized by a massive potentially usable waste heat flow are characteristic for the production of ferroalloys in electric arc furnaces.

Our proposed device is part of an energy system that performs cooling of exhaust fumes and at the same time acquires unused heat from the technological process of production of ferroalloys in an arc furnace. The device is developed and designed purposefully for use in specific location. It is composed of a furnace hat, door panels and ring, as is shown in Figure 1. The hat of the furnace is designed as a pressure vessel divided into three independent segments. The segments consist of a set of plate exchangers and a tubular structure. Each of the three segments consists of sheet panel coolers and of the tubular segment. Each segment is a separate group of pressure vessels. Radiator panels are largearea plate heat exchangers. The planar walls of the plate heat exchangers are suitable for the construction of thermal systems up to a temperature of $450{ }^{\circ} \mathrm{C}$. They are reinforced by a

* Corresponding author: richard.lenhard@fstroj.uniza.sk

Reviewers: Tomasz Domański, Milan Žmindák 
system of veneers between the walls. Inside the panel there are partitions that direct the water flow across the entire panel surface. Radiator panels are installed in three groups around the perimeter of the bottom of the hat. Each of the panels disposed in a pipe section forms a separate heat transfer system, the panel and the tube segment receive radiated heat from the furnace and through the hot water in the heat exchanger transmit it to the hot water circuit.

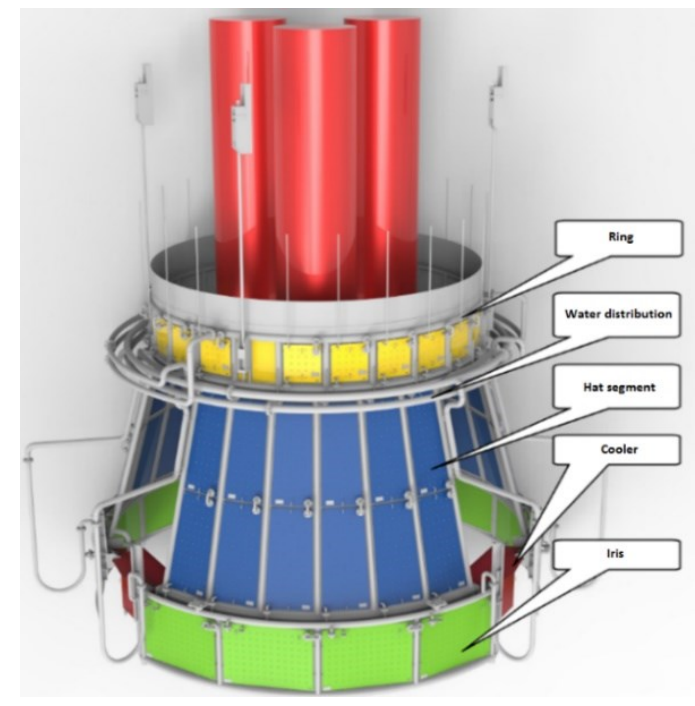

Fig. 1. Hat of furnace $-3 D$ sketch

\section{Numerical simulation of heat transfer}

Furnace model was developed in order to determine theoretical performance limits of the heat recovery system and to simulate the energy flow into the modified types of heat exchangers. The basic construction nodes, hat, aperture, flue gas volume and electrodes, served as input geometry for heat flow calculation [1]. The proposed model is shown in Figure 2.

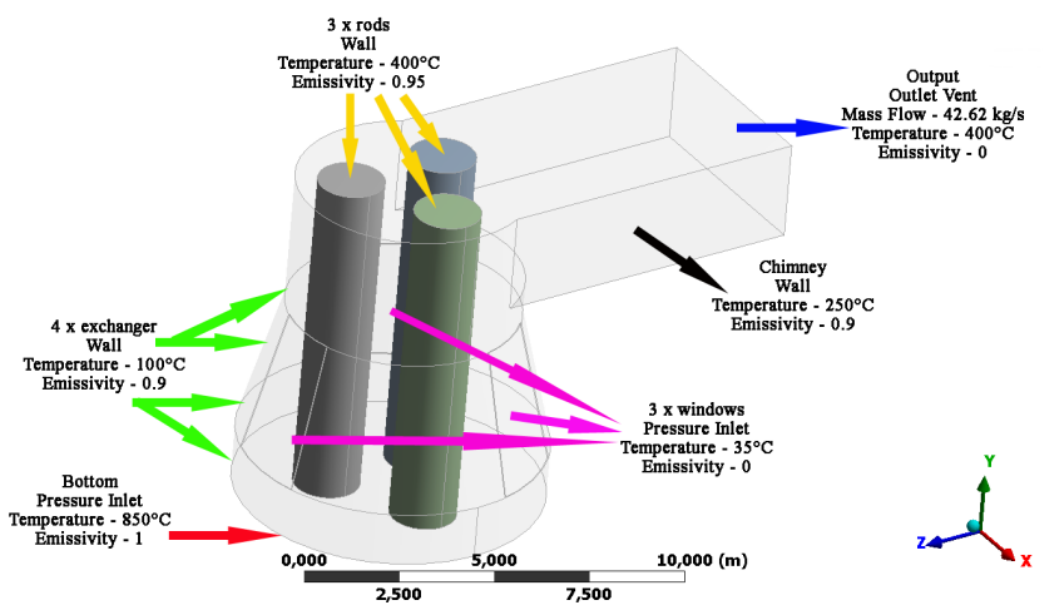

Fig. 2. Boundary conditions for the model 
A side effect of the proposed equipment is to reduce the exhaust flue temperature and to improve the working environment by lowering the temperature around the furnace. The electric arc and batch in the furnace is the source of heat radiation that is out of the furnace absorbed by the hat and in the space for loading between the hat and the floor around the furnace by three vertical movable curtains with heat exchangers. [2, 3]. Thermal radiation in the furnace is not constant, has a stochastic character and changes through time and space in the furnace, depends on the type of batch and on the skills and experience of the loading operator $[4,5,6]$. The creation of the furnace three dimensional models allowed numerical simulation of the energy flow into the heat exchangers in order to find out the heat recovery system performance. In Figure 2 are the input parameters for calculation of temperatures, velocities and heat flow. [7] The geometry of the simplified furnace was created in Design Modeller. The model system consists of 4 superposed cooling panels, see Figure 3, then of 3 electrodes, see Figure 4, with openings where the electrodes are supplied, and the coating, as in Figure 5, which replaces the cover of the openings with the electrodes themselves. The other parts of the furnace, e. g. the exhaust, was also presented, to display flue gas flow, see Figure 6 . The whole inner volume of the simplified furnace model was considered as fluid $[8,9]$.

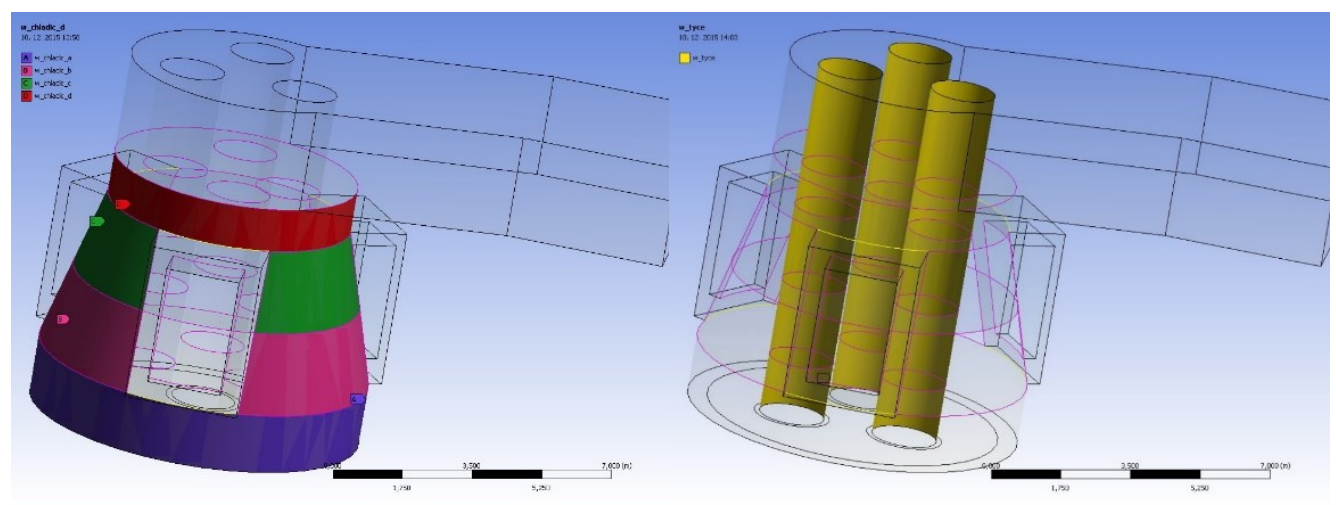

Fig. 3. Location of cooling panels

Fig. 4. Electrodes

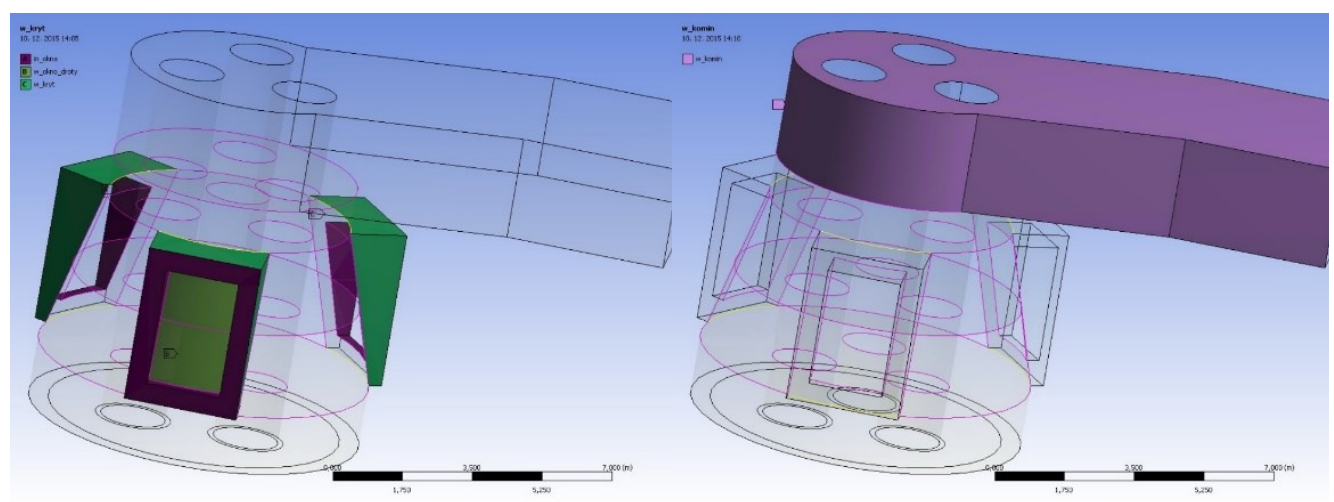

Fig. 5. Model of holes cover where the electrodes are fed

Fig. 6. Flue gas exhaust 


\section{Setup and numerical solution}

The computing mesh for the 3D simplified model was created in the Meshing module. The network itself contains 332564 cells. For the mesh creation a patch conforming method has been used to create tetrahedrons as shown in Figure 7. Also the higher crosslinking features Curvature and Proximity were used [10, 11].

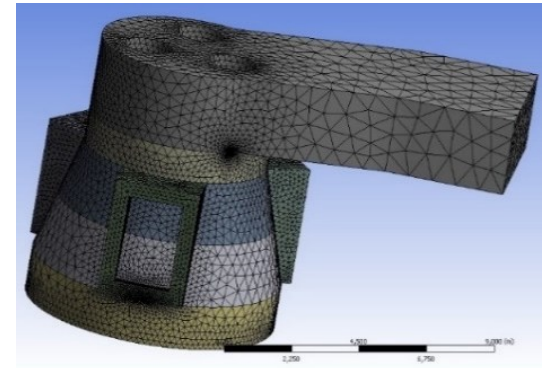

Fig. 7. Mesh before conversion

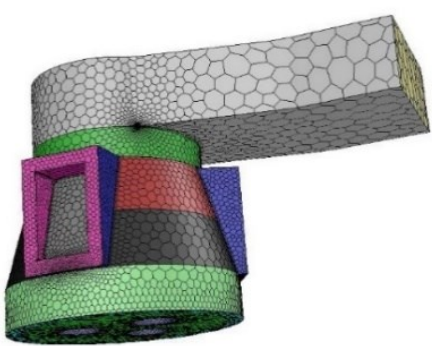

Fig. 8. Mesh converted to polyhedral mesh

To improve and accelerate numerical simulation, the network was further modified by converting to a polyhedral mesh. With this adjustment, we have achieved better job readability. The adjustment itself was done in the ANSYS Fluent software. The result is in Figure 8 . The $\mathrm{k}-\varepsilon$ turbulence model was chosen to perform the numerical simulation, with the realizable settings. Radiation model Discrete Ordinates with a 5 to 5 resolution has been turned on [12]. This model in the radiation transmission equation addresses radiation intensity that is positional and direction dependent [13]. Radiation is counted in each quadrant or octant. The handle transport equations are computed similarly as for flow and energy solutions. The simulation itself was performed in the ANSYS Fluent program with boundary conditions set according to Table 1 .

Table 1. Boundary conditions

\begin{tabular}{|c|c|c|c|c|}
\hline Name of boundary & Value entry & Velocity & Temperature & Emisivity \\
\cline { 2 - 5 } & Condition type & $\mathbf{k g} / \mathbf{s}$ & ${ }^{\circ} \mathbf{C}$ & \\
\hline in_ground & pressure-inlet & - & 1000 & 1 \\
\hline in_window & pressure-inlet & - & 35 & 0.5 \\
\hline out & outlet-vent & 42.62 & 400 & 0.5 \\
\hline w_cool_a & wall & - & 100 & 0.95 \\
\hline w_cool_b & wall & - & 100 & 0.95 \\
\hline w_cool_c & wall & - & 100 & 0.95 \\
\hline w_cool_d & wall & - & 100 & 0.95 \\
\hline w_ground_a & wall & - & 2000 & 1 \\
\hline w_ground_b & wall & - & - & 1 \\
\hline w_flue & wall & - & 250 & 0.9 \\
\hline w_cover & wall & - & - & 0.5 \\
\hline w_wind_wire & wall & - & - & 0.5 \\
\hline w_wire & wall & - & 400 & 0.95 \\
\hline
\end{tabular}


The flue gases were considered as the working medium, the walls of the model were designed as simplified surfaces with number of layers, thickness, temperature and emissivity.

Numerical simulation took place under standard operating conditions. In the simulations, a steady transfer of heat was assumed by the radiation from the molten layer (Table 1 in ground) of the selected parameters. To achieve the continuous rate of flue gas flow, the velocity was chosen at the outlet by specified temperature [14]. The calculation was considered as stationary.

\section{Results of numerical simulation}

The result of the simulation is the calculation of the radiation and convection component of the heat transfer into the four zones in the furnace hat. On the basis of entered boundary conditions, 2.5 megawatts have been obtained from the cooling panels, as is described in Table 2. The model is divided into 4 zones. The 1 st zone forms the cylindrical surface on which heat exchangers are designated as lifting aperture. The 2 nd zone consists of heat exchanger in the lower slanted part of the hat. The 3rd zone forms the heat exchanger in the top slanted part of the hat. The 4th zone forms the heat exchanger on the cylindrical ring at the top of the furnace hat.

Table 2. Total transferred heat power by exchangers

\begin{tabular}{|c|c|c|c|c|}
\hline $\begin{array}{c}\text { Name of } \\
\text { boundary }\end{array}$ & Zone & Power (W) & Surface ( $\left.\mathbf{m}^{\mathbf{2}}\right)$ & $\begin{array}{c}\text { Avg. } \\
\text { temperature } \\
(\mathbf{K})\end{array}$ \\
\hline w_cool_a & 1 & 1357596.9 & 39.584 & 869.546 \\
\hline w_cool_b & 2 & 619773.5 & 32.934 & 909.647 \\
\hline w_cool_c & 3 & 368621.97 & 25.6035 & 784.068 \\
\hline w_cool_d & 4 & 211761.59 & 21.426 & 651.34 \\
\hline summary & & 2557753.9 & 119.5475 & \\
\hline
\end{tabular}

The Figure 9, Figure 10, Figure 11 and Figure 12 show the resulting local temperature fields for individual parts of the cooling panels. From the obtained field temperature results it is possible to determine locations with local overheating, or to locate areas with higher cooling intensity due to the intake of outside air through the holes. In Figure 13, Figure 14, Figure 15 and Figure 16 the temperature fields are shown, where it is possible to monitor the influence of the outdoor air temperature passing through the openings into the furnace. The average temperature achieved in furnace based on entered boundary conditions is $1003 \mathrm{~K}$. The Figures 15 and Figure 16 show velocity fields, where it is possible to track the effect of the furnace structure on the flue gas flow in the furnace section planes. It can be seen from the results that the flow is uneven in the interior, which may in some places cause greater fouling of the surfaces with carbon and thus cause local temperature increase. 


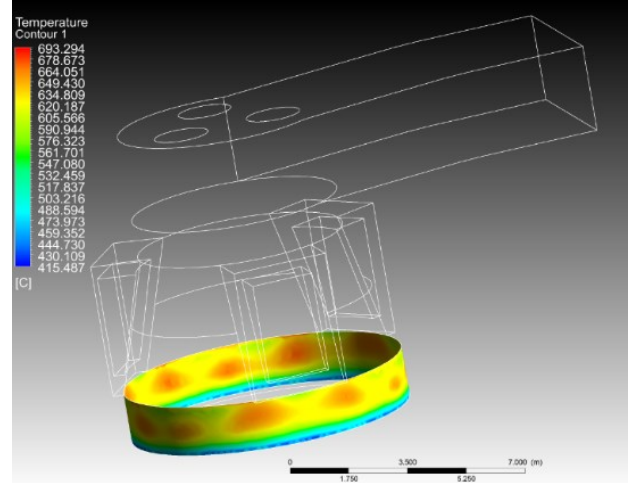

Fig. 9. Temperature fields of lower cooling panel -w_cool_a

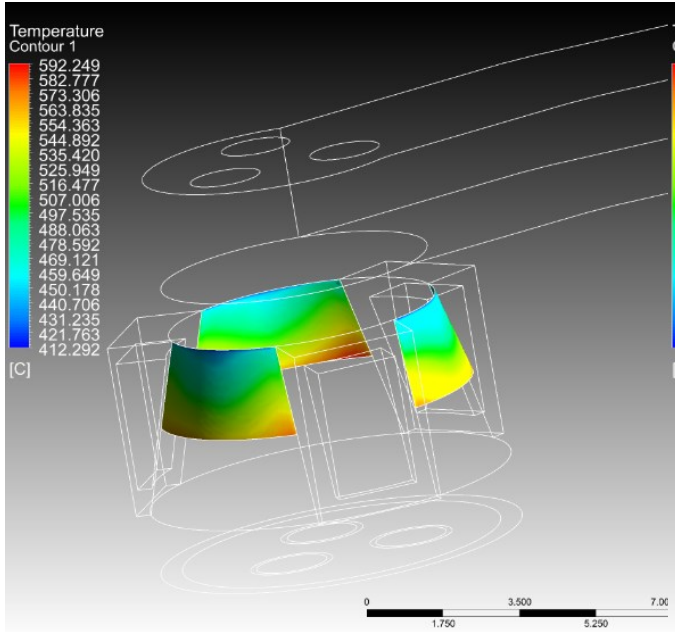

Fig. 11. Temperature fields of cooling panel w_cool_c

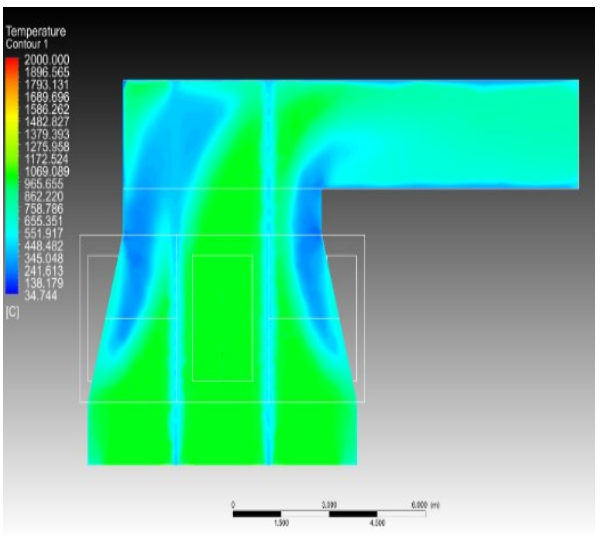

Fig. 13. Temperature fields in section area

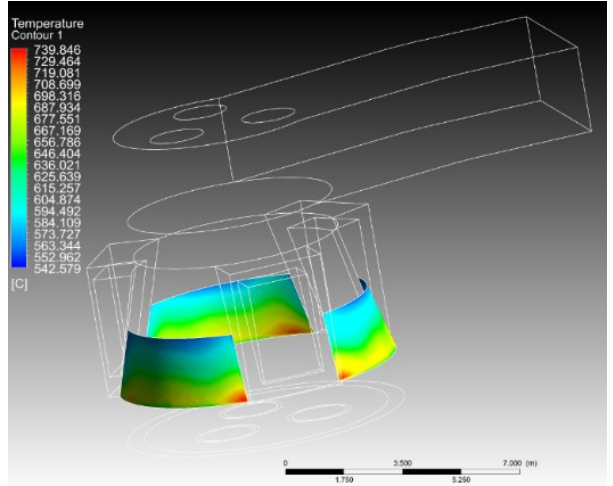

Fig. 10. Temperature fields of cooling panel w_cool_b

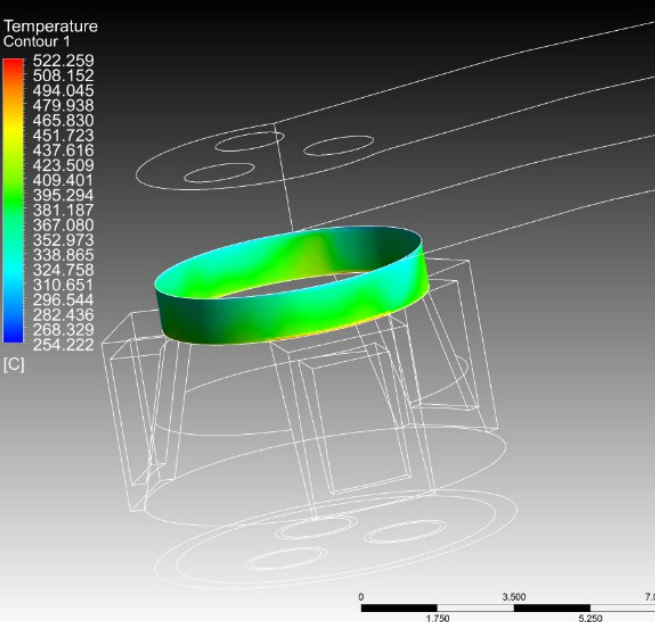

Fig. 12. Temperature fields of upper cooling panel - w_cool_d

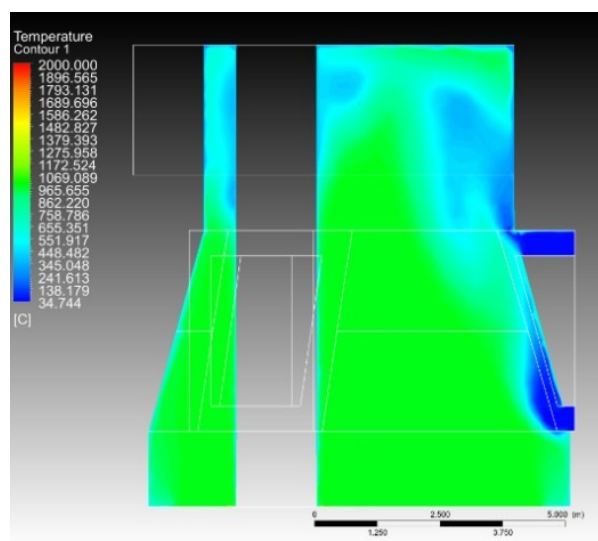

Fig. 14. Temperature fields in section area 


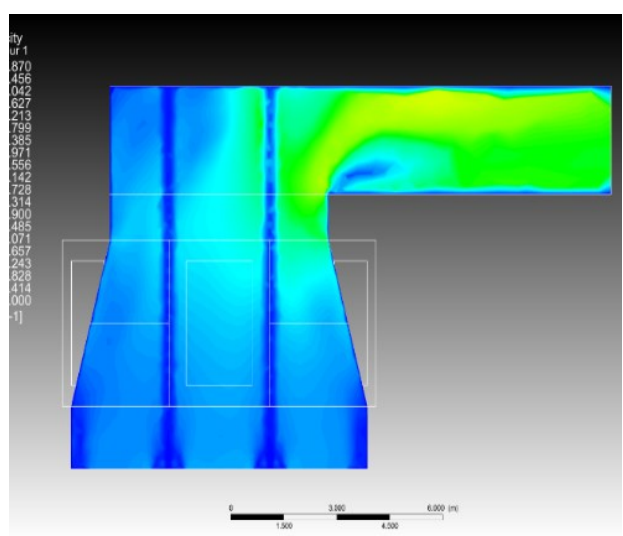

Fig. 15. Velocity fields in section area

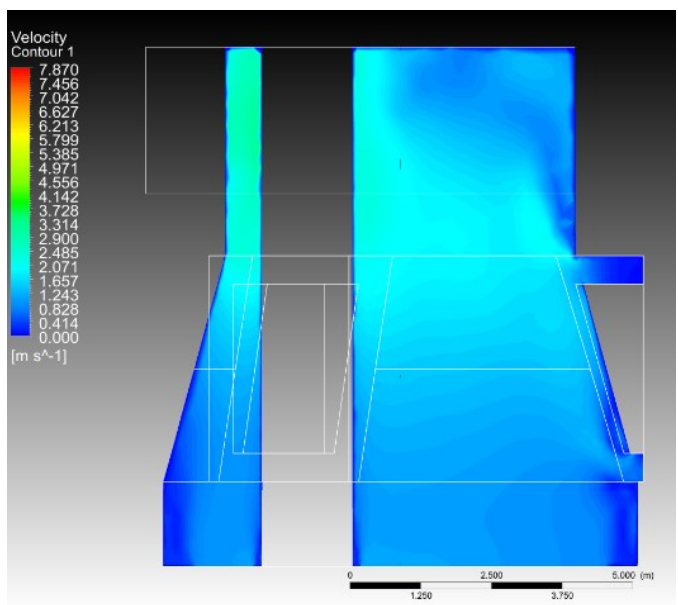

Fig. 16. Velocity fields in section area

\section{Conclusion}

The issue of recovering and using heat from electric arc furnaces is very wide and very complicated and requires some experience with this issue. Its solution should have a comprehensive approach not only to the way and form of heat generation, but also to the possibilities of its use. In our opinion, it is also necessary to propose technical solutions that accept the biggest problem of heat generation from electric arc furnaces hat - the heat exchange surface of the recuperation exchanger with a dust extraction of very specific properties, for example perfect sanding on uneven surfaces. This is also a significant restriction on the use of waste heat for the production of electricity, whether via water vapour or through the ORC cycle. Existing installations need a stable high potential heat source. Therefore, it may be necessary to deal with systems that are relatively simple and resistant to conditions in which they have to work reliably. It is possible to design significantly more physically efficient types of heat exchangers, compared to the present solution, but the functionality of such exchanger would be, as the experience has shown, already after several hours of operation question and especially their cleaning during operation is practically impossible. Great attention must be paid, in our opinion, to the quality regulation of the heat recovery equipment, which must respond flexibly to the nonstationary nature of the exchanger control resulting from the loading method of the furnace.

The research is supported from the project "APVV-15-0778 - The limits of conventional radiation and cooling through the phase change of the working fluid in the thermo-syphon loop".

This contribution is the result of the project implementation: Slovak Infrastructure for High Performance Computing, ITMS code 26230120002, supported by the Research \& Development Operational Programme funded by the ERDF.

\section{References}

1. ANSYS Help Viewer, Version: 17.2.0. (2016)

2. P. Durcansky, P. Hrabovsky, M. Malcho, Waste heat recovery system with heat pipe through phase change in a small biomass furnace. SGEM (2016)

3. R. Nosek, S. Gavlas, R. Lenhard, V. Sedlak, H. M. Arvesen, Condenser optimization of heat pipe. Communications 16, 62-66 (2014) 
4. M. Malcho, J. Jandačka, R. Lenhard, S. Gavlas, T. Ochodek, Numerical simulation of heat transport from the electric arc furnace to the heat recovery system. Communications 18, 115-121 (2016)

5. VDI heat atlas, Verein Deutscher Ingenieure, VDI-Gesellschaft Verfahrenstechnik und Chemieingenieurwesen (GVC), $2^{\text {nd }}$ ed., 1585 p. (Springer, Heidelberg, 2010)

6. T. Brestovič, M. Čarnogurská, R. Pyszko, M. Kubik, Effect of radiation on heat exchange in finned heat transfer surfaces. XVIII Intern. scientific conference The application of experimental and numerical methods in fluid mechanics and energy, 1926 (2012)

7. B. Skočilasová, J. Skočilas, Determination of pressure drop coefficient by CFD simulation. Proc. of AIP Conference 1608, 206-210 (2014)

8. J. Kňourek, R. Matas, O. Prokeš, D. Tenkrát, Numerical simulations of natural gas flow in pipe system with flowmeters. EPJ Web of Conferences, 67 (2013)

9. A. Kapjor, K. Kaduchová, R. Lenhard, H. Smatanová, Prenos tepla z orientovaných teplovýmenných plôch pri prirodzenej konvekcii. ISBN 978-80-554-1304-4 (2017)

10. J. Černecký, J. Koniar, The study of heat transfer in narrow gaps at low Reynold's number values. Acta facultatis technicae 13, 75-82 (2009)

11. E. Pivarčiová, J. Černecký, Vizualizácia teplotných polí a prúdenia. Aplikácia experimentálnych a numerických metód v mechanike tekutín, 194-198 (2002)

12. M. Brůna, A. Sládek, Nové trendy v oblasti numerickej simulácie pre zlievarenstvo. Technológ (2011)

13. Z. Trávníček, P. Dančová, J.H. Lam, V. Timchenko, J. Reizes, Numerical and experimental studies of a channel flow with multiple circular synthetic jets. EPJ Web of Conferences (2012)

14. W. Adamczyk, F. Szelejewski, P. Kozolub, R. Białecki, T. Kruczek, CFD estimation of heat losses in thermal conductivity measurements. Computer Assisted Mechanics and Engineering Sciences (2013) 